Article

\title{
Dynamics of Volunteering and Life Satisfaction in Midlife and Old Age: Findings from 12 European Countries
}

\author{
Thomas Hansen ${ }^{1, *}$, Marja Aartsen ${ }^{1}$, Britt Slagsvold ${ }^{1}$ and Christian Deindl ${ }^{2}$ \\ 1 Norwegian Social Research (NOVA), OsloMet-Oslo Metropolitan University, 0167 Oslo, Norway, \\ marja.aartsen@oslomet.no (M.A.); britt.slagsvold@oslomet.no (B.S.) \\ 2 Institute of Sociology, TU Dortmund University, 44227 Dortmund, Germany; \\ christian.deindl@tu-dortmund.de \\ * Correspondence: thomas.hansen@oslomet.no; Tel.: +47-9766-4509
}

Received: 20 March 2018; Accepted: 29 April 2018; Published: 4 May 2018

\begin{abstract}
A growing literature shows that doing voluntary work not only helps the wider community but can also improve one's own well-being. To date, however, few studies have examined the relationship between volunteering and well-being in non-US and especially in comparative data. We study this relationship using two waves of data of 18,559 individuals aged 50 and above from 12 European countries. We analyze life satisfaction impacts of change and stability in volunteering status and in the intensity (frequency) of volunteering, and explore whether these impacts differ according to life stage (age, employment status) and across countries with different norms and supports for voluntarism. Findings show that net life satisfaction is higher among longer-term, recent, and former volunteers than among stable (long-term) non-volunteers. There are no significant life satisfaction differences between the three groups with volunteer experience. Equally, similar levels of life satisfaction are observed among people who have increased and decreased their frequency of volunteering. It thus seems to be the experience and not the dynamics (i.e., change or persistence) of volunteering that is associated with well-being. Findings further suggest life course variation in the association between volunteering and well-being, as the relationship is stronger for older and long-term non-employed (mostly retired) individuals than for their middle-aged and working counterparts. The relationship is also stronger in countries where volunteering is less common and less institutionally supported.
\end{abstract}

Keywords: volunteering; older adults; life satisfaction; Europe

\section{Introduction}

With the ageing of the population, stimulating and enabling older people to remain actively engaged in society sit high on Western political agendas (Walker and Maltby 2012). Voluntary work provides a viable arena for social contributions and engagement in late life. Volunteering is a generic term that refers to different types of helping behaviors that people undertake of their free will and without being paid, to people outside of their household. One way to categorize these activities is by their formality (Wilson and Musick 1997). Formal volunteering is any contribution of time and energy to activities of organizations. Informal volunteering refers to help given directly, not mediated by formal organizations, for instance to a friend or a neighbor (Lee and Brudney 2012). In Europe, the rate of volunteering among older adults varies considerably across countries. The rate of seniors (age 60-79) who have done voluntary work at least monthly during the last year ranges from two to three percent in southern countries such as Spain and Greece to $20-22 \%$ in northern countries such as the Netherlands and the Nordic countries (Erlinghagen and Hank 2006; Hank and Stuck 2008). 
The contribution of older volunteers is believed to benefit not only communities and society but also older people themselves (WHO 2002; Principi et al. 2014). This expectation is tied to at least three factors. First, that engaging in prosocial behavior may generate a greater sense of meaning, competence, self-worth, and personal growth. Furthermore, that the physical activity aspect of volunteering may have important health benefits and protect against health problems. Last, that volunteering may broaden opportunities for positive social exchanges and social support (Pilkington et al. 2012). However, the gains could be balanced or outweighed by any potentially negative aspects of volunteering, such as role conflict and excessive time and energy demands.

There are several reasons for expecting that older people might experience greater benefits of volunteering than middle-aged adults. First, older people, particularly if they are retired, should be less prone to time strains and stress from multiple role obligations. Second, whereas younger people may be expected to do some voluntary work as part of their work and parent roles, volunteering may be more truly "voluntary" and intrinsically motivated in older age (Van Willigen 2000). A similar point is that the nature of the activities is also different, as elders may be freer to choose the types of voluntary work they find interesting and rewarding. US data suggest that older volunteers may benefit more because they are active in the more psychologically beneficial types of voluntary work, such as church-based voluntarism and senior center voluntarism (Van Willigen 2000). Finally, voluntary work may play a particularly useful role in protecting against inactivity and physical decline among older people (Fischer and Schaffer 1993). Seniors are less likely to have other social roles to keep them active, socially integrated, and feeling productive (Van Willigen 2000). Indeed, older volunteers often report benefits and joys from doing voluntary work. In a US study, almost 8 out of 10 older volunteers agreed that voluntarism had enhanced their well-being and provided them with a larger social network. Three out of four said they now used their time more meaningfully (Wilson and Musick 1999; Morrow-Howell et al. 1999).

A vast literature confirms that volunteering is cross-sectionally associated with different indicators of mental health and well-being among older adults (see Anderson et al. 2014; Casiday et al. 2008; Von Bonsdorff and Rantanen 2011 for reviews). However, the causal order is not clear from these studies (Anderson et al. 2014). A growing number of prospective studies of the impact of volunteering on well-being has emerged, mostly based on US data. Some of these studies indicate that volunteering improves aspects of psychological outcomes, such as depression, happiness, and life satisfaction (Li and Ferraro 2006; Musick and Wilson 2003; Piliavin and Siegl 2007; Thoits and Hewitt 2001; Van Willigen 2000). Similar effects have also been found in studies from Australasian countries (Mellor et al. 2009; Schwingel et al. 2009; Windsor et al. 2008). Some data also demonstrate that older adults (age 60+) receive greater mental health and life satisfaction benefits from volunteering than middle-aged adults (Kim and Pai 2010; Li and Ferraro 2006; Van Willigen 2000). Musick and Wilson (2003), for example, found that volunteering decreased depression, but only for the 65+ age group. Yet there are studies of older adults that fail to confirm prospective effects of volunteering on life satisfaction and happiness (Menec 2003) or depression (Shmotkin et al. 2003). Several studies have also examined bidirectional effects. It has been found that seniors with better health, social and economic resources, and higher self-esteem are more likely to become volunteers (Anderson et al. 2014; Li and Ferraro 2005). Some prospective studies of older adults only find evidence of well-being influencing volunteering, and not vice versa (Son and Wilson 2012). It is thus still unclear whether volunteering improves psychological well-being.

The literature on the relationship between volunteering and well-being has several other gaps. First, few non-US and especially cross-national comparative studies exist. Little is thus known about whether the effect of volunteering varies with cultural and institutional contexts. There are several reasons to expect country differences in the association between volunteering and well-being. First, the degree to which volunteering is encouraged, supported, and practiced may matter. In countries where voluntarism is more normative and prevalent, such as the Northern European countries, the activity may be especially rewarding because people may derive 
satisfaction and self-approval by conforming to social norms and a sense of "doing one's duty". Volunteers in a low-volunteering country may not experience the same social recognition and "moral" rewards. Furthermore, in low-volunteering countries, those who contribute may not expect their contribution to be reciprocated, which is found to be a condition for positive benefits of volunteering (McMunn et al. 2009). Similarly, in these countries, the fact that few others volunteer may generate feelings of unfairness and resentment among those who are active in this way. Second, volunteer satisfaction has been shown to depend upon institutional support for the activity (Strom and Strom 1995). Voluntarism may thus be more beneficial when governments encourage and support voluntary work, as in the northern European countries. Without such support volunteering may be less attractive and more of a burden. These notions aside, arguments can also be made for the benefits being lower in high-volunteering countries and stronger welfare states. In these countries, volunteers may feel less needed; if they do not deliver the services, the state or someone else will (Haski-Leventhal 2009). Concomitantly, in low-volunteering countries, the few who volunteer may feel more special and receive more favorable social feedback. It may also be that in these countries, perhaps because of missing infrastructure for volunteering, only those who are highly motivated and most likely to benefit from volunteering actually volunteer. Hence, in these countries a strong association between well-being and volunteering might reflect selection into volunteering rather than causal effects. In sum, it is an empirical question whether and how the benefits of volunteering vary across nations and by different macro-level characteristics.

Second, there is limited knowledge about life course variation in the associations between volunteering and well-being. Some studies indicate that associations are stronger or only evident among older (60+) individuals, but findings are mixed (Anderson et al. 2014; Jenkinson et al. 2013). Few studies have explored the moderating role of other life course markers, such as retirement. Theoretical arguments about age-differences (see above) often center, however, on retirement and not age. As retirement may be more likely to affect the benefits of volunteering than age per se, the role of retirement should be examined more directly.

Third, there is limited knowledge, especially in a cross-national setting, about how volunteering effects may depend on the dynamics in the volunteer role. Little is for example known about the role of consistency of volunteering; whether the benefits are larger for those who have volunteered regularly over a longer period of time and whether effects of volunteering disappear when volunteering is discontinued. US research suggests gradually stronger benefits the longer time (the more data waves) older people have volunteered (Piliavin and Sieg1 2007; Wilson and Musick 1999). US and UK data also indicate that the positive effects of volunteering disappear when volunteering is discontinued (Binder and Freytag 2013; Meier and Stutzer 2008).

Finally, few studies explore the effect of frequency of volunteering. A role theory perspective would argue that the frequency of volunteering may be inconsequential because people derive satisfaction merely from thinking of themselves, and being seen by others, as a volunteer (Son and Wilson 2012). By contrast, insofar as there are benefits of the actual volunteer activity, there could be a "dose-response" relationship between frequency of volunteering and well-being (Son and Wilson 2012). Doing too much volunteering, on the other hand, could lead to strain and decreased well-being. Indeed, US findings suggest that high levels of volunteer activity may have diminishing returns or perhaps even harmful effects on late-life well-being (Van Willigen 2000).

This study examines associations between voluntary work and life satisfaction in data from 12 European countries. The overarching aim is to assess whether volunteering is associated with greater well-being and if the association varies by level of volunteering, life stage, and country. We address the above-mentioned gaps in the literature by asking the following questions: What is the effect of change (commencing, ending) and continuity in volunteering on life satisfaction? What is the relationship between (change in) intensity of volunteering and life satisfaction? Do effects of volunteering vary across age groups and between working and non-working individuals? Are the effects different in countries with different rates, cultures, and institutional supports of volunteering? 


\section{Materials and Methods}

\subsection{Data}

This study combines harmonized data from two datasets: the Survey of Health, Ageing and Retirement (SHARE) and the Norwegian study on Life course, Ageing, and Generation (NorLAG). SHARE has a representative sample of the population aged 50 and over in Sweden, Denmark, the Netherlands, Belgium, France, Germany, Austria, Switzerland, Spain, Italy, and Greece (Börsch-Supan 2017; Börsch-Supan et al. 2013). We use data from the first wave (w1) and second wave (w2) of SHARE, collected in 2004-2005 and 2006-2007, respectively. Of the original w1 sample, 66\% $(n=18,742)$ participated in both waves. All data are collected by face-to-face, computer-aided personal interviews (CAPI), supplemented by a self-completion paper-and-pencil questionnaire. NorLAG comprises representative data of Norwegians aged 40-80 (at w1). Data were collected in 2002-2003 (w1) and 2007-2008 (w2) by means of a combination of phone interview, postal questionnaire, and registry information (Slagsvold et al. 2012). The w1 response rate was $67 \%(n=5559)$, of which $72 \%(n=3796)$ took part at w2 (combined response rate $48 \%$ ). Together the analytical sample comprises longitudinal information about 18,559 respondents (16,953 from SHARE and 1606 from NorLAG) aged above 50 from 12 countries (listwise deletion).

\subsection{Dependent and Independent Variables}

Our dependent variable is life satisfaction at w2. It is measured with a single item: "On a scale from 0 to 10 where 0 means completely dissatisfied and 10 means completely satisfied, how satisfied are you with your life?"

Voluntary work is in SHARE measured by asking if respondents have done voluntary or charity work in the past month (yes/no). Those answering yes were then asked to report the frequency of their participation, from "almost daily" (1) to "never" (5). NorLAG asks how often respondents have done voluntary work for an association or organization, from "daily" (1) to "never" (6). We classify respondents as (regular) volunteers if they volunteered monthly or more often, and as non-volunteers if they did not volunteer or volunteered less than monthly. Based on this classification we define four groups of change in volunteer status: stable non-volunteer (non-volunteer in both waves), stable (longer-term) volunteer (volunteer in both waves), becoming a volunteer (non-volunteer at w1, volunteer at w2), and cessation of volunteering (volunteer at w1, non-volunteer at w2).

We also consider change in the intensity (frequency) of voluntary work. We use the following categories: stable non-volunteer (not volunteering or volunteering < monthly in both waves), stable activity (volunteering at the same level-monthly, weekly, or daily-in both waves), less intense (volunteering $\geq$ monthly at w1 and not volunteering or volunteering $<$ monthly at w2), and more intense (volunteering monthly or no activity at w1, volunteering $>$ monthly at w2).

\subsection{Control Variables}

To account for factors that may influence simultaneously life satisfaction and volunteering, we include in the analysis a set of control variables (for an overview of the association of socio-demographic and other factors with volunteering, see (Wilson and Musick 1997)). We control for age and gender, and for change in partnership status (yes/no), as partnered individuals have been shown to do voluntary work more often than their non-partnered counterparts (ibid.). We also control for socioeconomic status (SES), which tends to be positively linked with volunteering (ibid.). SES is indicated by education (high = tertiary) and subjective financial situation at w2 (ability to make ends meet, 1-4). We control also for change in employment status (working/non-working) from w1 to w2. Work status is included as a control because volunteering may compete with paid work for individuals' time and effort.

Health may interfere with people devoting time and effort to volunteering. We therefore account for change in subjective health and functional health. Subjective health, or self-rated general health 
status, is measured with the response categories ranging from poor (1) to excellent (5). We also measure longitudinal change $(\mathrm{w} 2-\mathrm{w} 1)$ in subjective health. This results in the score 0 if no change occurred and positive (negative) values for improved (reduced) health. Functional health is measured as limitations with activities of daily life. SHARE asks, "For the past six months, to what extent have you been limited in your daily activities because of a health problem? Responses include severely limited, limited but not severely, and not limited. NorLAG asks, "Does your health now limit you a lot, or a little, in tasks like moving a table, vacuuming, walking, or gardening?" Individuals are classified as "limited" if they report at least some limitations ("limited but not severely" in SHARE and "a little" in NorLAG). Scores are categorized into: no limitations in both waves; no limitations at w1, limitations at w2; limitations in both waves; and limitations at w1, no limitations at w2.

The covariates also include an indicator of psychological well-being at w1, a measure of depressive symptoms to control for baseline well-being (results are similar when we use a single-item measure of happiness; not shown). Depressive symptoms is measured using the z-standardized scores on two similar depression scales: for SHARE the EURO-D scale (Prince et al. 1999) and for NorLAG the 20-item Center for Epidemiologic Studies Depression scale (Radloff 1977). We also include "time between waves" to control for country differences in the time span between data waves.

We use information about country-level rate of volunteering and social spending. Countries are classified as low, medium, and high (based on tertiles) in terms of social spending (measured in US dollars per capita) and rate of volunteering (see Table 1 below). This information is derived from OECD (2016) and European Values Survey (EVS 2016).

Table 1. Country-level social spending and rate of volunteering.

\begin{tabular}{ccccc}
\hline & Social Spending & Classification & Rate of Volunteering & Classification \\
\hline Norway & $12,889.9$ & High & 38.81 & High \\
Sweden & $10,968.3$ & Medium & 30.41 & Medium \\
Denmark & $12,109.2$ & High & 37.03 & High \\
Netherlands & 9891.0 & Medium & 46.85 & High \\
Belgium & $11,123.6$ & High & 34.00 & Medium \\
Germany & $10,466.5$ & Medium & 23.76 & Low \\
Austria & $11,555.9$ & High & 26.49 & Medium \\
Switzerland & 9428.5 & Low & 36.56 & High \\
France & $11,014.9$ & Medium & 25.98 & Medium \\
Spain & 8367.4 & Low & 12.87 & Low \\
Italy & 9502.7 & Low & 23.04 & Low \\
Greece & 6905.2 & Low & 15.53 & Low \\
\hline
\end{tabular}

Source: OECD (2016); EVS (2016).

\section{Results}

Table 2 shows the prevalence of regular (monthly or more often) volunteering for each country at w1 and w2. Findings reveal a north-south gradient with the highest rates in the north-west (20-30\%) and the lowest in the south-east of Europe $(<10 \%)$. Intra-country rates of volunteering are somewhat higher at w2 than at w1, but the inter-country differences are stable across waves. Table 2 also shows the prevalence of change in regular (monthly or more often) volunteer work from w1 to w2 for each country. We find higher rates of both starting and quitting volunteering in the Nordic countries than in southern Europe. Similarly, having increased their frequency of volunteering from w1 to w2 is more common in the north-west than in the south-east. As shown, weekly and monthly volunteering but not daily volunteering is more common in the north-west than in the south-east.

Table 3 shows associations between volunteering and life satisfaction. We find that stable volunteering, entering volunteering, and exiting volunteering are all associated with significantly higher life satisfaction (at w2) than stable non-volunteering. Supplementary tests (not shown) indicate no significant differences in life satisfaction between the three groups with current or volunteering 
experience. Hence, although life satisfaction at $\mathrm{w} 2$ is somewhat lower among former volunteers than among current volunteers, this difference is not statistically significant at the 0.05 level. When introducing controls for individuals-level covariates we explain some of the differences in life satisfaction between people with volunteering experience and stable non-volunteers, but do not alter the (non-significant) differences between the three groups with volunteer experience.

Table 4 presents the results of analyses of change in the intensity of volunteering. Similarly to before, the main difference in life satisfaction is evident between people with volunteering experience and stable non-volunteers. There are no significant differences between groups of individuals who have become more or less active volunteers. This pattern is not affected by controlling for potential covariates of volunteering.

Tables 3 and 4 together show the results of eight interaction effects (all ps $<0.05$ ). These interactions are illustrated using marginal effect plots in Figures 1-8. Overlap of the error bars indicates whether there are significant differences or not. The difference in life satisfaction between those with and those without volunteer experience is only significant in the oldest age group (65+) (Figures 1 and 2), among the (long-term) non-employed (Figures 3 and 4), in countries with a low-medium level of social spending (Figures 5 and 6), and in countries with a low rate of volunteering (Figures 7 and 8). 
Table 2. Prevalence (\%) of volunteering and various levels of volunteering at first wave (w1), second wave (w2), and between-wave change.

\begin{tabular}{|c|c|c|c|c|c|c|c|c|c|c|c|c|c|c|c|}
\hline \multirow[b]{3}{*}{ Country (N) } & \multicolumn{4}{|c|}{ W1 } & \multicolumn{4}{|c|}{ W2 } & \multicolumn{7}{|c|}{ W1 to W2 } \\
\hline & \multirow[b]{2}{*}{$\begin{array}{c}\text { Not } \\
\mathbf{a}\end{array}$} & \multirow[b]{2}{*}{ Monthly } & \multirow[b]{2}{*}{ Weekly } & \multirow[b]{2}{*}{ Daily } & \multirow[b]{2}{*}{$\operatorname{Not}^{a}$} & \multirow[b]{2}{*}{ Monthly } & \multirow[b]{2}{*}{ Weekly } & \multirow[b]{2}{*}{ Daily } & \multicolumn{4}{|c|}{ Active ( $\geq$ Monthly) Volunteering } & \multicolumn{3}{|c|}{ Intensity of Volunteering ${ }^{b}$} \\
\hline & & & & & & & & & $\begin{array}{l}\text { Inactive in } \\
\text { Both Waves }\end{array}$ & $\begin{array}{l}\text { Active Both } \\
\text { Waves }\end{array}$ & $\begin{array}{l}\text { Inactive } \\
\rightarrow \text { Active }\end{array}$ & $\begin{array}{l}\text { Active } \rightarrow \\
\text { Inactive }\end{array}$ & $\begin{array}{l}\text { Stable } \\
\text { Level }^{\mathrm{c}}\end{array}$ & Less $^{d}$ & More $^{e}$ \\
\hline Norway (1606) & 74.2 & 15.6 & 8.9 & 1.4 & 68.4 & 16.7 & 13.3 & 1.6 & 61.2 & 18.4 & 13.1 & 7.4 & 12.5 & 9.3 & 17.1 \\
\hline Sweden (1927) & 80.7 & 8.2 & 8.4 & 2.8 & 77.7 & 8.9 & 10.0 & 3.5 & 70.7 & 12.3 & 10.0 & 7.0 & 6.4 & 9.4 & 13.5 \\
\hline Denmark (1091) & 80.3 & 7.8 & 10.1 & 1.8 & 76.4 & 8.8 & 11.5 & 3.4 & 68.8 & 12.2 & 11.5 & 7.5 & 7.1 & 9.4 & 14.7 \\
\hline Netherlands (1587) & 76.1 & 5.6 & 14.5 & 3.8 & 73.9 & 5.7 & 16.3 & 4.0 & 66.5 & 16.5 & 9.6 & 7.4 & 10.8 & 9.8 & 12.9 \\
\hline Belgium (2559) & 82.1 & 5.9 & 8.5 & 3.5 & 82.4 & 5.8 & 8.5 & 3.3 & 76.1 & 11.7 & 6.0 & 6.3 & 7.3 & 8.6 & 8.0 \\
\hline Germany (1467) & 86.1 & 5.2 & 6.2 & 2.5 & 84.9 & 4.8 & 8.1 & 2.2 & 78.8 & 7.8 & 7.3 & 6.1 & 4.4 & 7.6 & 9.1 \\
\hline Austria (1051) & 90.0 & 4.8 & 4.9 & 0.4 & 90.4 & 4.8 & 4.2 & 0.7 & 84.0 & 3.6 & 6.0 & 6.4 & 2.2 & 7.2 & 6.6 \\
\hline Switzerland (642) & 84.9 & 6.4 & 6.9 & 1.9 & 82.9 & 6.4 & 8.3 & 2.5 & 75.2 & 7.5 & 9.7 & 7.6 & 3.9 & 9.2 & 11.7 \\
\hline France (1652) & 82.6 & 5.2 & 7.9 & 4.3 & 83.8 & 5.2 & 7.4 & 3.6 & 76.3 & 9.9 & 6.3 & 7.5 & 5.2 & 10.4 & 8.1 \\
\hline Spain (1278) & 97.1 & 1.7 & 0.6 & 0.6 & 97.1 & 0.9 & 1.3 & 0.7 & 95.4 & 1.2 & 1.7 & 1.7 & 0.6 & 1.8 & 2.2 \\
\hline Italy (1597) & 92.1 & 2.8 & 3.8 & 1.4 & 92.0 & 2.8 & 3.4 & 1.9 & 87.7 & 3.6 & 4.4 & 4.3 & 2.3 & 4.8 & 5.3 \\
\hline Greece (2103) & 96.5 & 1.7 & 1.4 & 0.5 & 98.0 & 1.1 & 0.8 & 0.1 & 95.7 & 1.2 & 0.8 & 2.3 & 1.1 & 2.4 & 0.9 \\
\hline Pooled $(18,560)$ & 85.1 & 5.9 & 6.9 & 2.2 & 84.0 & 5.9 & 7.7 & 2.3 & 78.2 & 9.1 & 6.9 & 5.8 & 5.5 & 7.4 & 8.9 \\
\hline
\end{tabular}

a Not volunteering or volunteering less often than monthly. ${ }^{\mathrm{b}}$ Stable inactive is excluded as it can be read from the "Inactive in both waves" column. c Stable level (monthly, weekly, or daily). ${ }^{d} \geq$ Monthly at $w 1,<$ monthly at w2. ${ }^{\text {e }} \leq$ Monthly at w1, $>$ monthly at $w 2$.

Table 3. Regressing life satisfaction on change in volunteer status, individual- and macro-level controls, and interaction terms.

\begin{tabular}{|c|c|c|c|c|}
\hline & Volunteer Status & + Individual-Level Factors & + Country Social Spending & + Country Rate of Volunteering \\
\hline \multicolumn{5}{|c|}{ Volunteer status (VS) (ref: inactive in both waves) } \\
\hline Active in both waves & $0.61^{* *}$ & $0.32 * *$ & $0.27 * *$ & $0.24^{* * *}$ \\
\hline Active at $\mathrm{w} 2$ (starting) & $0.64^{* *}$ & 0.35 ** & 0.31 ** & 0.28 ** \\
\hline Active at $w 1$ (quitting) & $0.43^{* *}$ & 0.22 ** & $0.18^{* *}$ & $0.16^{* *}$ \\
\hline Male & & $-0.14 * *$ & -0.14 ** & $-0.15^{* *}$ \\
\hline Age & & $0.01 * *$ & $0.01 * *$ & $0.01^{* *}$ \\
\hline High education & & 0.01 & -0.01 & -0.01 \\
\hline \multicolumn{5}{|c|}{ Financial situation (ref: great difficulty) } \\
\hline Difficult & & $0.54^{* * *}$ & $0.49 * *$ & $0.49^{* * *}$ \\
\hline Easy & & $1.01^{* *}$ & $0.90^{* *}$ & $0.87^{* * *}$ \\
\hline Very easy & & $1.42 * *$ & $1.27^{* *}$ & $1.20^{* *}$ \\
\hline Change in subjective health & & $0.07 * *$ & $0.07 * *$ & $0.07 * *$ \\
\hline \multicolumn{5}{|c|}{ Functional health (ref: no health limitations) } \\
\hline Limitation in both waves & & $-0.26^{* *}$ & $-0.29 * *$ & $-0.28 * *$ \\
\hline Limitations in wave 2 & & $-0.53 * *$ & $-0.56^{* *}$ & $-0.55 * *$ \\
\hline Limitations in wave 1 & & 0.02 & 0.00 & -0.00 \\
\hline
\end{tabular}


Table 3. Cont.

\begin{tabular}{|c|c|c|c|c|}
\hline & Volunteer Status & + Individual-Level Factors & + Country Social Spending & + Country Rate of Volunteering \\
\hline \multicolumn{5}{|c|}{ Partner status (ref: no partner both waves) } \\
\hline Partner both waves & & $0.33 * *$ & $0.35 * *$ & $0.36 * *$ \\
\hline Partner in wave 2 & & 0.51 ** & $0.49 * *$ & $0.50 * *$ \\
\hline Partner in wave 1 & & $-0.24^{* *}$ & $-0.24^{* *}$ & $-0.24^{* *}$ \\
\hline \multicolumn{5}{|c|}{ Employment status (ref: not employed both waves) } \\
\hline Employed both waves & & $0.20 * *$ & $0.19 * *$ & $0.17^{* *}$ \\
\hline Employed in wave 2 & & $0.30 * *$ & $0.29 * *$ & $0.28 * *$ \\
\hline Employed in wave 1 & & $0.11 *$ & $0.09 *$ & 0.08 \\
\hline Time between waves & & $0.01 * *$ & $0.01 * *$ & 0.00 \\
\hline Depressive symptoms (wave 1 ) & & $-0.36^{* *}$ & $-0.37 * *$ & $-0.37^{* *}$ \\
\hline \multicolumn{5}{|c|}{ Country social spending/rate of vol. (ref: low) } \\
\hline Medium & & & $0.26 * *$ & $0.29 * *$ \\
\hline High & & & 0.32 ** & 0.53 ** \\
\hline \multicolumn{5}{|l|}{ VS interactions } \\
\hline VS $\times$ Age group & & & $4.45^{* *}$ & \\
\hline VS $\times$ Employment status & & & 2.24 * & \\
\hline VS $\times$ Social spending & & & $2.89 * *$ & \\
\hline VS $\times$ Rate of volunteering & & & & $3.77 * *$ \\
\hline $\mathrm{R}^{2}$ & 0.02 & 0.23 & 0.23 & 0.24 \\
\hline
\end{tabular}

Notes: Unstandardized regression coefficients or $F$-values. Interaction effects were tested entering one pair of predictors at a time in the regression equations. All parameters are $F$-values (with controls for main effects). ${ }^{* *} p<0.01, * p<0.05$

Table 4. Regressing life satisfaction on change in volunteering intensity, individual- and macro-level controls, and interaction terms.

\begin{tabular}{|c|c|c|c|c|}
\hline & Volunteering Intensity & + Individual-Level Factors & + Country Social Spending & + Country Rate of Volunteering \\
\hline \multicolumn{5}{|c|}{ Volunteering intensity (VI) (ref: stable inactive) } \\
\hline Stable intensity & $0.57 * *$ & $0.30 * *$ & $0.25 * *$ & $0.21 * *$ \\
\hline Decreasing activity & $0.46^{* *}$ & $0.25^{* *}$ & $0.21 * *$ & $0.19 * *$ \\
\hline Increasing activity & $0.66^{* *}$ & $0.35 * *$ & $0.31 * *$ & $0.27^{* *}$ \\
\hline \multicolumn{5}{|l|}{ VI interactions } \\
\hline $\mathrm{VI} \times$ Age group & & & $3.96^{* *}$ & \\
\hline VI $\times$ Employment status & & & $1.95 *$ & \\
\hline $\mathrm{VI} \times$ Social spending & & & $2.63 * *$ & \\
\hline $\mathrm{VI} \times$ Rate of volunteering & & & & $3.53 * *$ \\
\hline $\mathrm{R}^{2}$ & 0.02 & 0.23 & 0.23 & 0.24 \\
\hline
\end{tabular}

Notes: Unstandardized regression coefficients or $F$-values. Controls (same as in Table 2) not shown. Interaction effects were tested entering one pair of predictors at a time in the regression equations. All parameters are $F$-values (with controls for main effects). ${ }^{* *} p<0.01,{ }^{*} p<0.05$. 


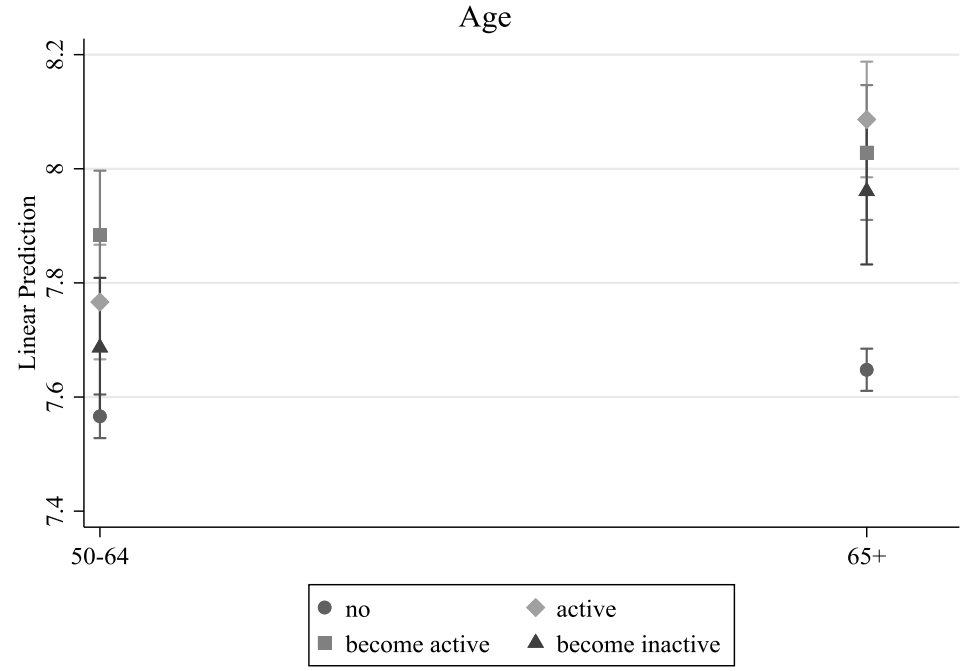

Figure 1. Predicted life satisfaction in volunteer groups by age group.

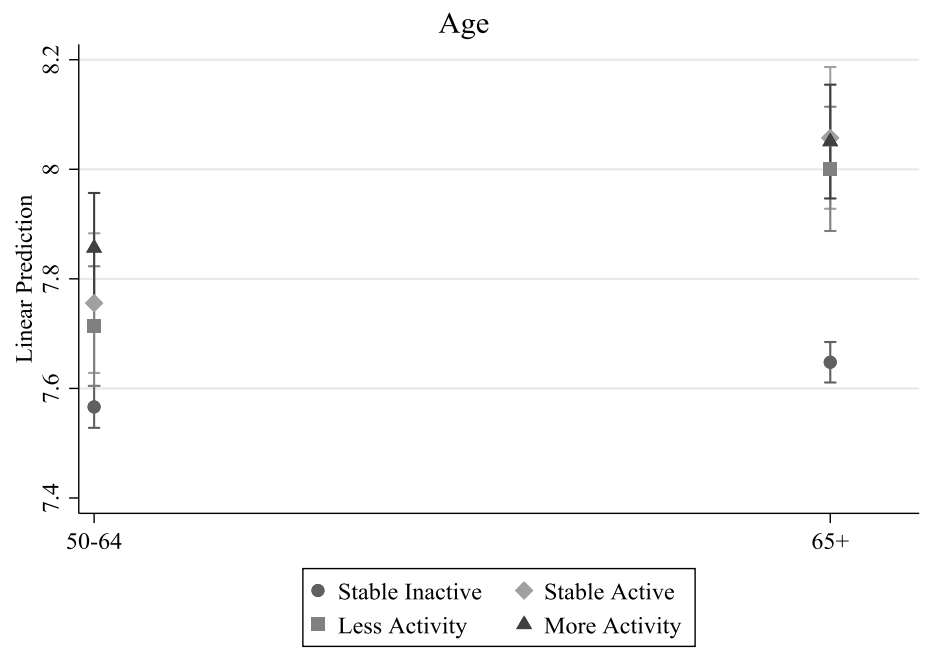

Figure 2. Predicted life satisfaction in volunteering intensity groups by age group.

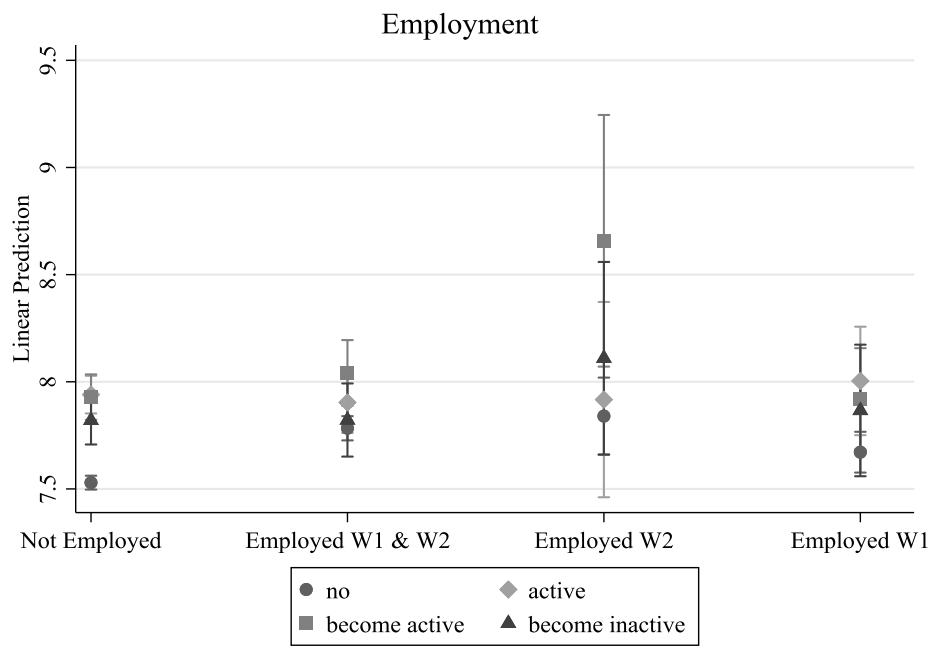

Figure 3. Predicted life satisfaction in volunteer groups by employment status. 


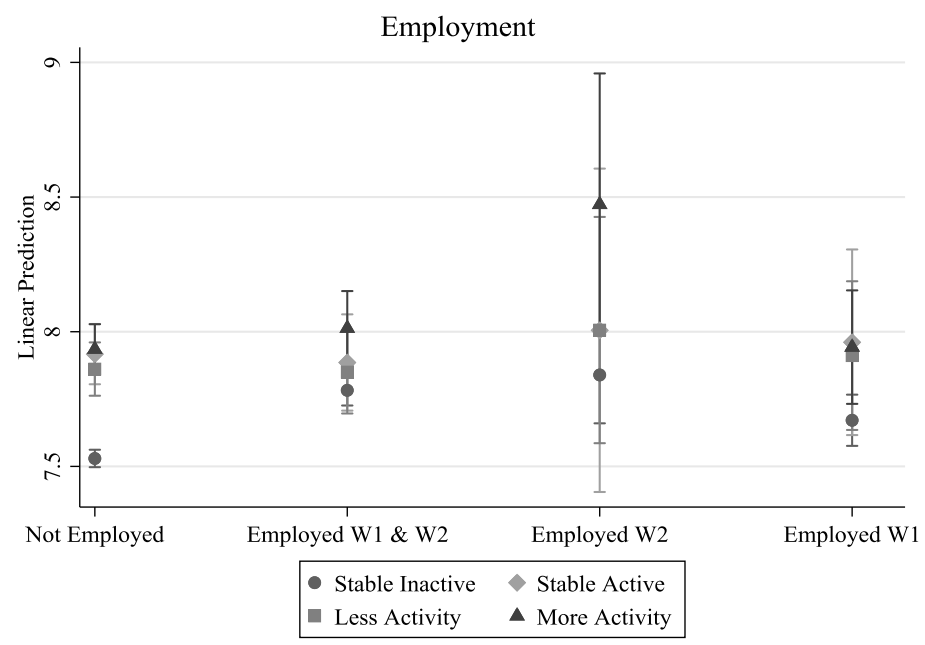

Figure 4. Predicted life satisfaction in volunteering intensity groups by employment status.

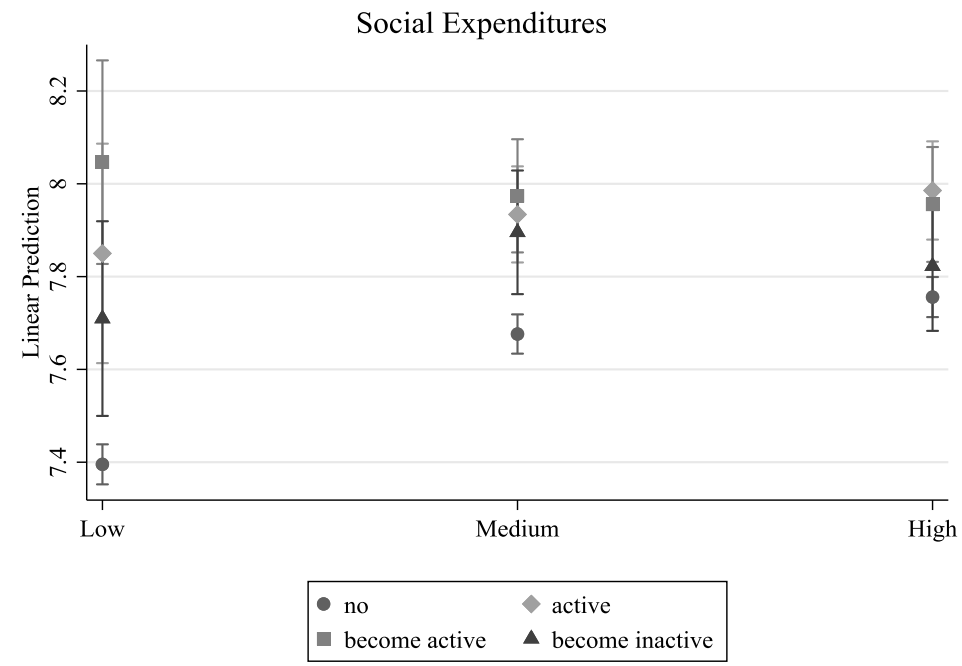

Figure 5. Predicted life satisfaction in volunteer groups by country-level social spending.

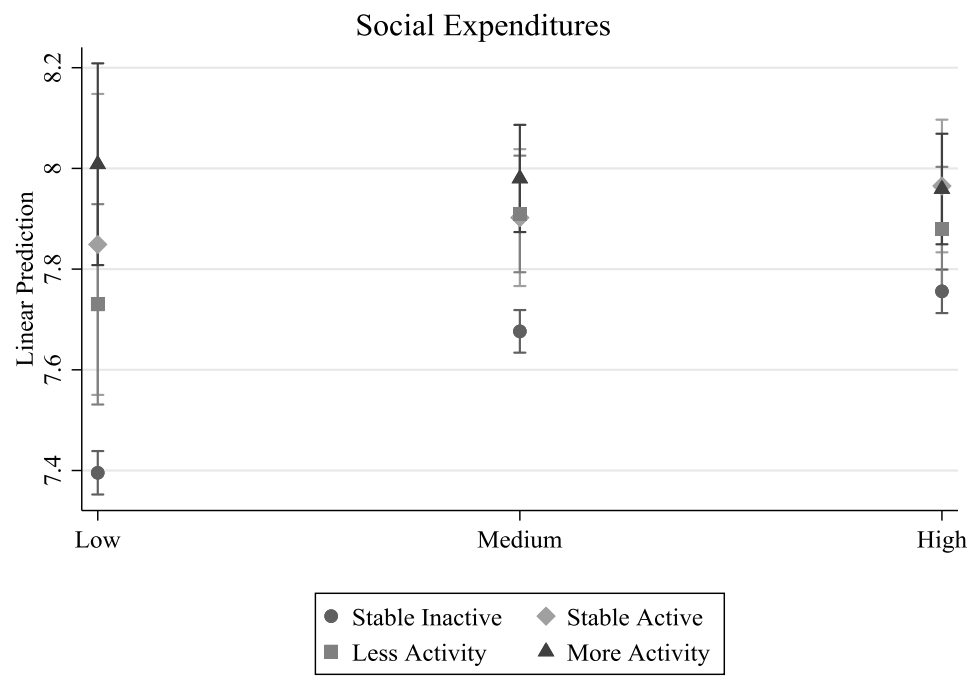

Figure 6. Predicted life satisfaction in volunteering intensity groups by country-level social spending. 


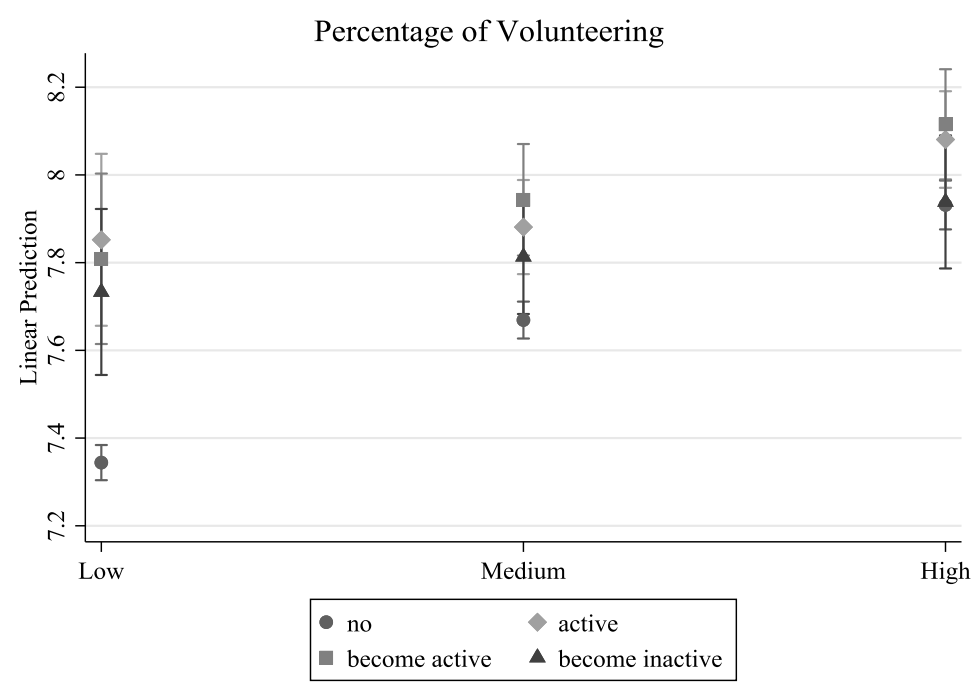

Figure 7. Predicted life satisfaction in volunteer groups by country-level rate of volunteering.

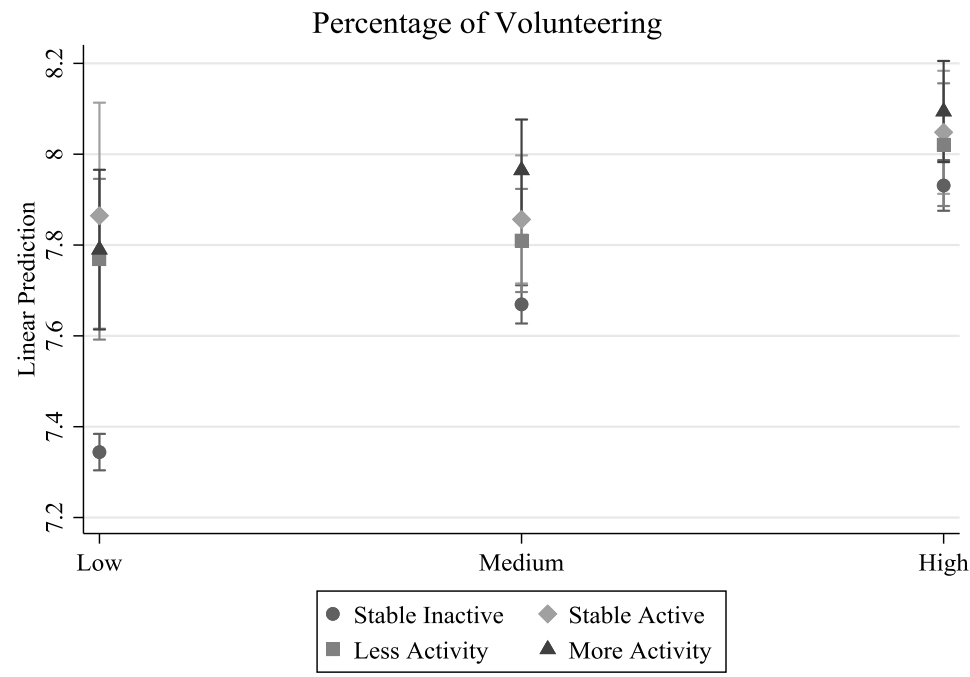

Figure 8. Predicted life satisfaction in volunteering intensity groups by country-level rate of volunteering.

\section{Discussion}

This study explores associations between volunteering and life satisfaction among individuals aged 50 and older in 12 European countries. More specifically, we examine how life satisfaction relates to stability and change in (i) volunteering status and (ii) intensity (frequency) of volunteering. We also examine whether effects differ by age and employment status, and across countries with different macro-level characteristics.

Findings show that stable volunteering, entering volunteering, and exiting volunteering are all associated with higher life satisfaction (at w2) than stable non-volunteering. There are no significant life satisfaction differences between the three groups with current or prior volunteering experience. Similarly, in the analyses of associations between change in intensity of volunteering and life satisfaction, the main difference in terms of life satisfaction is evident between stable non-volunteers and people with volunteering experience. Change in the frequency of volunteering does not seem to play a major role, as there are no significant differences between groups of individuals who have become more or less active volunteers.

The lack of an association between frequency of volunteering and satisfaction seemingly negates a dose-response relationship between volunteering and well-being. Similarly, the observation that prior 
volunteering has similar associated benefits as initiated or consistent volunteering also casts doubt on causal linkage between volunteering and life satisfaction. Overall, the results thus seem driven by selection of high-satisfaction individuals into volunteering rather than by volunteering having a clear impact on life satisfaction. Selection may, for example, explain the relatively high satisfaction among people who have exited or reduced their volunteer role. Consistent with this interpretation, a similar previous longitudinal study only found support for selection, not causation effects (Son and Wilson 2012).

A different interpretation is that our findings may also reflect causation. Most previous research have shown simultaneous selection and causation effects (Anderson et al. 2014; Li and Ferraro 2005). The high satisfaction among former volunteers may reflect that volunteering can have salutary effects on, for example, self-esteem, health, and social integration that last well beyond the actual time spent volunteering. Volunteering thus may matter, even if one stops doing it.

Findings furthermore suggest life course variation in the association between volunteering and life satisfaction. Involvement in regular volunteering is associated with life satisfaction only among the older (age 65+) and the longer-term non-employed, most whom are likely to be retired, but not among the employed and/or younger people. Age seems to have a stronger moderating role than employment status. This suggests that the associations come to the fore as a result of general age-related losses in roles and relationships rather than the loss of employment specifically. It should be noted, however, that the magnitude of these moderator effects is quite small and may be of limited practical importance.

Finally, findings indicate some systematic differences in the associations between volunteering and life satisfaction depending on country-level characteristics. Volunteering is more strongly associated with life satisfaction in countries with low social spending and low rate of volunteering. It is unclear whether this pattern reflects stronger selection or causation mechanisms in these countries than in stronger welfare states. Regarding causation, findings may indicate that volunteering is particularly beneficial in low-volunteering countries with their low level of public funding and support of volunteering. In these countries, volunteers may feel more special and needed; if they do not deliver the services, neither the state nor anyone else will (Haski-Leventhal 2009). Concomitantly, the few who volunteer in these countries may receive significant positive social feedback. These experiences may in turn influence life satisfaction through self- and relational esteem. Regarding selection, it may be that in low-volunteering countries, perhaps because of missing infrastructure for volunteering, people who are highly motivated and with physical and psychological resources are most likely to volunteer. Hence, in these countries a strong association between well-being and volunteering might reflect selection into volunteering rather than causal effects.

An important limitation of the current study is that we did not have information on life satisfaction at w1, which might have helped decipher the causation-selection issue. In lieu of life satisfaction at $\mathrm{w} 1$, and in an attempt to model change in life satisfaction, we have included a measure of depressive symptoms as an indicator of psychological well-being at w1. Although this measure correlates significantly with life satisfaction $(r=-0.30)$, depressive symptoms are arguably a poor proxy for life satisfaction. That said, we found a relationship between volunteering and satisfaction that was not predicted by baseline levels of depressive symptoms, suggesting that there is at least some component of the relationship between satisfaction and participation for which participation temporally precedes satisfaction.

Some other limitations also warrant mentioning. There are some concerns over the comparability of harmonized data. For example, the fact that waves of data collection are spaced by two years in SHARE and five years in NorLAG could affect the results. Also, questions about volunteering and other factors are posed somewhat differently in the two surveys. However, the fact that results are similar for Norway (NorLAG) and Sweden (SHARE) suggests that these inconsistencies do not play a major role for our main conclusions.

Furthermore, we lack proper measurement of public spending on volunteering and quality of infrastructures of volunteering. We have used social spending as an indicator of these aspects, as social spending has been shown to be strongly associated with a country's financial and institutional 
support of volunteering (CEV 2012). Future research should aim to use direct measures of state-level volunteering supports and policies.

We are also limited in the scope of well-being indicators. First, in addition to a measure of the cognitive aspect of well-being (life satisfaction), we would have liked to examine affective dimensions such as positive and negative affect. Second, we are also unable to examine the effect of volunteering on the eudaimonic conception of well-being, which has become influential in recent years (e.g., Ryan and Deci 2001; Seligman 2002). Essential to eudaimonic well-being is engagement in challenging and meaningful activities, especially those activities that require substantial effort and incorporate a concern for others and "the greater good" (ibid.). Volunteering may be considered one such "worthwhile cause". Existential dimensions of well-being, such as meaning, purpose in life, growth, and development, are important outcome variables in the eudaimonic approach to well-being. Because these outcomes are closely linked to the volunteering experience, future research should investigate theoretical and empirical links between volunteering and eudaimonic well-being.

\section{Conclusions}

Our findings indicate that people who are currently or previously involved with volunteering report higher well-being than people without such experience. This pattern is more pronounced with older age and in countries where volunteering is less common and less institutionally supported. Although we cannot rule out the possibility of causation mechanisms, there seems to be more support for the notion that volunteering is selective of individuals who already have high well-being. While some observers have claimed that greater community involvement is a win-win situation, benefiting not only the wider community but also the volunteers, this study and prior studies suggest more caution is needed.

Author Contributions: The authors together conceived of the idea of the paper. T.H. reviewed the literature and wrote the paper (except Methods). C.D. wrote the methodology, harmonized the data, and conducted the analyses. B.S. and M.A. acquired funding for the project and commented on drafts of the paper.

Acknowledgments: This paper uses data from SHARE Waves 1, 2, 3 (SHARELIFE), 4, 5 and 6 (DOIs: 10.6103/SHARE.w1.600, 10.6103/SHARE.w2.600, 10.6103/SHARE.w3.600, 10.6103/SHARE.w4.600, 10.6103/SHARE.w5.600, 10.6103/SHARE.w6.600), see Börsch-Supan et al. (2017) for methodological details. The SHARE data collection has been primarily funded by the European Commission through FP5 (QLK6-CT-2001-00360), FP6 (SHARE-I3: RII-CT-2006-062193, COMPARE: CIT5-CT-2005-028857, SHARELIFE: CIT4-CT-2006-028812) and FP7 (SHARE-PREP: Nº 211909, SHARE-LEAP: N²27822, SHARE M4: N²61982). Additional funding from the German Ministry of Education and Research, the Max Planck Society for the Advancement of Science, the US National Institute on Aging (U01_AG09740-13S2, P01_AG005842, P01_AG08291, P30_AG12815, R21_AG025169, Y1-AG-4553-01, IAG_BSR06-11, OGHA_04-064, HHSN271201300071C) and from various national funding sources is gratefully acknowledged (see www.share-project.org).

Conflicts of Interest: The authors declare no conflict of interest. The funding sponsors had no role in the design of the study; in the collection, analyses, or interpretation of data; in the writing of the manuscript, and in the decision to publish the results.

\section{References}

Anderson, Nicole D., Thecla Damianakis, Edeltraut Kröger, Laura M. Wagner, Deirdre R. Dawson, Malcolm A. Binns, Syrelle Bernstein, Eilon Caspi, and Suzanne L. Cook. 2014. The benefits associated with volunteering among seniors: A critical review and recommendations for future research. Psychological Bulletin 140: 1505-33. [CrossRef] [PubMed]

Binder, Martin, and Andreas Freytag. 2013. Volunteering, subjective well-being and public policy. Journal of Economic Psychology 34: 97-119. [CrossRef]

Börsch-Supan, Axel. 2017. Survey of Health, Ageing and Retirement in Europe (SHARE) Wave 1. Release version: 5.0.0. SHARE-ERIC Data Set. [CrossRef]

Börsch-Supan, Axel, Martina Brandt, Christian Hunkler, Thorsten Kneip, Julie Korbmacher, Frederic Malter, Barbara Schaan, Stephanie Stuck, and Sabrina Zuber. 2013. Data resource profile: The Survey of Health, Ageing and Retirement in Europe (SHARE). International Journal of Epidemiology 42: 992-1001. [CrossRef] [PubMed] 
Casiday, Rachel, Eileen Kinsman, Clare Fisher, and Clare Bambra. 2008. Volunteering and Health; What Impact Does It Really Have. London: Volunteering England.

CEV. 2012. Volunteering Infrastructure in Europe. Brussels: European Volunteer Centre.

Erlinghagen, Marcel, and Karsten Hank. 2006. The participation of older Europeans in volunteer work. Ageing $\mathcal{E}$ Society 26: 567-84.

EVS. 2016. European Values Study 2008: Integrated Dataset (EVS 2008). GESIS Data Archive, Cologne. ZA4800 Data file Version 4.0.0. Mannheim: GESIS. [CrossRef]

Fischer, Lucy Rose, and Kay Banister Schaffer. 1993. Older Volunteers: A Guide to Research and Practice. Thousand Oaks: Sage Publications, Inc.

Hank, Karsten, and Stephanie Stuck. 2008. Volunteer work, informal help, and care among the 50+ in Europe. Social Science Research 37: 1280-91. [CrossRef] [PubMed]

Haski-Leventhal, Debbie. 2009. Elderly volunteering and well-being: A cross-European comparison based on SHARE data. Voluntas: International Journal of Voluntary and Nonprofit Organizations 20: 388-404. [CrossRef]

Jenkinson, Caroline E., Andy P. Dickens, Kerry Jones, Jo Thompson-Coon, Rod S. Taylor, Morwenna Rogers, Clare L. Bambra, Iain Lang, and Suzanne H. Richards. 2013. Is volunteering a public health intervention? A systematic review and meta-analysis of the health and survival of volunteers. BMC Public Health 13: 773-84. [CrossRef] [PubMed]

Kim, Joongbaeck, and Manacy Pai. 2010. Volunteering and Trajectories of Depression. Journal of Aging and Health 22: 84-105. [CrossRef] [PubMed]

Lee, Young-joo, and Jeffrey L. Brudney. 2012. Participation in formal and informal volunteering: Implications for volunteer recruitment. Nonprofit Management and Leadership 23: 159-80. [CrossRef]

Li, Yunqing, and Kenneth F. Ferraro. 2005. Volunteering and depression in later life: Social benefit or selection processes? Journal of Health and Social Behavior 46: 68-84. [CrossRef] [PubMed]

Li, Yunqing, and Kenneth F. Ferraro. 2006. Volunteering in middle and later life: Is health a benefit, barrier or both? Social Forces 85: 497-519. [CrossRef]

McMunn, Anne, James Nazroo, Morten Wahrendorf, Elizabeth Breeze, and Paola Zaninotto. 2009. Participation in socially-productive activities, reciprocity and wellbeing in later life: Baseline results in England. Ageing and Society 29: 765-82. [CrossRef]

Meier, Stephan, and Alois Stutzer. 2008. Is volunteering rewarding in itself? Economica 75: 39-59. [CrossRef]

Mellor, David, Yoko Hayashi, Mark Stokes, Lucy Firth, Lucy Lake, Michael Staples, Sue Chambers, and Robert Cummins. 2009. Volunteering and its relationship with personal and neighborhood well-being. Nonprofit Voluntary Sector Quarterly 38: 144-59. [CrossRef]

Menec, Verena H. 2003. The relation between everyday activities and successful aging: A 6-year longitudinal study. The Journals of Gerontology Series B: Psychological Sciences and Social Sciences 58: S74-82. [CrossRef]

Morrow-Howell, Nancy, Susan Kinnevy, and Marylen Mann. 1999. The perceived benefits of participating in volunteer and educational activities. Journal of Gerontology and Social Work 32: 65-80. [CrossRef]

Musick, Marc A., and John Wilson. 2003. Volunteering and depression: The role of psychological and social resources in different age groups. Social Science \& Medicine 56: 259-69. [CrossRef]

OECD. 2016. Society at a Glance. OECD Social Indicators. Paris: OECD Publishing. [CrossRef]

Piliavin, Jane Allyn, and Erica Siegl. 2007. Health benefits of volunteering in the Wisconsin longitudinal study. Journal of Health and Social Behavior 48: 450-64. [CrossRef] [PubMed]

Pilkington, Pamela D., Tim D. Windsor, and Dimity A. Crisp. 2012. Volunteering and subjective well-being in midlife and older adults: The role of supportive social networks. Journals of Gerontology Series B: Psychological Sciences and Social Sciences 67: 249-60. [CrossRef] [PubMed]

Prince, Martin J., Friedel Reischies, A. T. Beekman, Rebecca Fuhrer, Catholijn Jonker, Sirkka-Liisa Kivela, Brian A. Lawlor, Antonio Lobo, H. Magnusson, and M. Fichter. 1999. Development of the EURO-D scale-A European Union initiative to compare symptoms of depression in 14 European centres. The British Journal of Psychiatry 174: 330-38. [CrossRef] [PubMed]

Principi, Andrea, Per H. Jensen, and Giovanni Lamura, eds. 2014. Active Ageing: Voluntary Work by Older People in Europe. Bristol: Policy Press.

Radloff, Lenore Sawyer. 1977. The CES-D scale: A self-report depression scale for research in the general population. Applied Psychological Measurements 1: 385-401. [CrossRef] 
Ryan, Richard M., and Edward L. Deci. 2001. On happiness and human potentials: A review of research on hedonic and eudaimonic well-being. Annual Review of Psychology 52: 141-66. [CrossRef] [PubMed]

Schwingel, Andiara, Mathew M. Niti, Catherine Tang, and Tze Pin Ng. 2009. Continued work employment and volunteerism and mental well-being of older adults: Singapore longitudinal ageing studies. Age E Ageing 38: 531-37.

Seligman, Martin E.P. 2002. Authentic Happiness: Using the New Positive Psychology to Realize Your Potential for Lasting Fulfillment. New York: Free Press.

Shmotkin, Dov, Tzvia Blumstein, and Baruch Modan. 2003. Beyond keeping active: Concomitants of being a volunteer in old-old age. Psychology and Aging 18: 602-7. [CrossRef] [PubMed]

Slagsvold, Britt, Marijke Veenstra, Svein Olav Daatland, Gunhild Hagestad, Thomas Hansen, Katharina Herlofson, Kristine Koløen, and Per Erik Solem. 2012. Life-course, ageing and generations in Norway: The NorLAG study. Norsk Epidemiologi 22: 95-102. [CrossRef]

Son, Joonmo, and John Wilson. 2012. Volunteer Work and Hedonic, Eudemonic, and Social Well-Being. Sociological Forum 27: 658-81. [CrossRef]

Strom, Robert D., and Shirley K. Strom. 1995. Intergenerational learning: Grandparents in the schools. Educational Gerontology: An International Quarterly 21: 321-35. [CrossRef]

Thoits, Peggy A., and Lyndi N. Hewitt. 2001. Volunteer work and well-being. Journal of Health and Social Behavior 42: 115-31. [CrossRef] [PubMed]

Van Willigen, Marieke. 2000. Differential benefits of volunteering across the life course. The Journals of Gerontology Series B: Psychological Sciences and Social Sciences 55: S308-18. [CrossRef]

Von Bonsdorff, Mikaela B., and Taina Rantanen. 2011. Benefits of formal voluntary work among older people. A review. Aging Clinical and Experimental Research 23: 162-69. [CrossRef] [PubMed]

Walker, Alan, and Tony Maltby. 2012. Active ageing: A strategic policy solution to demographic ageing. International Journal of Social Welfare 21: 117-30. [CrossRef]

WHO. 2002. Active Ageing: A Policy Framework 2002. Geneva: WHO.

Wilson, John, and Marc Musick. 1997. Who cares? Toward an integrated theory of volunteer work. American Sociological Review 5: 694-713. [CrossRef]

Wilson, John, and Marc Musick. 1999. The effects of volunteering on the volunteer. Law and Contemporary Problems 62: 141-68. [CrossRef]

Windsor, Timothy D., Kaarin J. Anstey, and Bryan Rodgers. 2008. Volunteering and psychological well-being among young-old adults: How much is too much? Gerontologist 48: 59-70. [CrossRef] [PubMed] 